phenyl mercuric acetate, methyl mercuric chloride were reduced with $\operatorname{tin}(\mathrm{II})$ after addition of $10 \mathrm{ml}$ of $10 \mathrm{M}$ sodium hydroxide and traces of $\mathrm{Cu}(\mathrm{II})$ ion (alkali method). The ratio of the stained length to the amounts of mercury compounds in water by the acid method was equal to that by the alkali method.

The length of a stain had a difinite value in correspondence to the amounts of mercury in water when the volume of aeration for separating mercury from water attained to $600 \sim 700 \mathrm{ml}$ at the average velocity $75 \sim$ $150 \mathrm{ml} / \mathrm{min}$.

Interference of the reduction of mercury compounds with coexisting substances in alkali method was smaller than that in the acid method except when silver ions were present. When nitrous ions were present more than $10 \mathrm{ppm}$ nitrogen dioxide was generated and disturbed the determination of mercury by the acid method, because nitrogen dioxide produce a stain similar to that produced by mercury (grayish yellow or pale orange). However, the stains of hydrogen sulfide (pale brown) and ammonia (light blue) which were generated from sulfide ions in the acid method and ammonium ions in the alkali method, respectively were distinguishable from that of mercury.

This method was applied to the analysis of submicrogram amounts of mercury in waste waters and river waters. In the majority of cases the results approximately agreed with those obtained by atomic absorption spectrophotometoric method with wet digestion.

The range of determination was $0.05 \sim 0.7 \mu \mathrm{g}$ of $\mathrm{Hg}$ in $50 \mathrm{ml}$ and the coefficient of variation was $5 \%$ at $14 \mathrm{ppb}$ level. The time required for a sample was about 8 minutes.

(Received May 8, 1974)

\title{
ジアンチピリル-2-ヒドロキシフェニルメタンを用いる チタンの吸光光度定量
}

\author{
石 井 一*，樋口 俊範**
}

(1974 年 5 月 11 日受理)

\begin{abstract}
チタン (IV) は水ーメタノール系酸性溶液中でジアンチピリルー2-ヒドロキシフェニルメタン (DHPM) と反応して $347 \mathrm{~nm}$ 付近に吸収極大を有する安定な黄色錯体を形成する。この錯体生成に及ぼす酸濃 度，DHPM 濃度，メタノール濃度などの影響につき検討して微量チタンの定量方法を確立した。少な くともチタン濃度 $4.8 \mathrm{ppm}$ までは検量線は直線となり，モル吸光係数は $9.1 \times 10^{3} \mathrm{l} / \mathrm{mol} \cdot \mathrm{cm}$ でっ た. 多量のジルコニウムは妨害するが，その他の通常のイオンは妨害しないので本法はきわめて実用的 な方法と考えられ，カオリン中のチタンの定量に応用して満足しうる結果を得た.

なお，チタン(IV)-DHPM 錯体は過塩素酸イオンの存在下でジクロル亡タンに定量的に抽出された のでチタンの抽出吸光光度定量についても検討して定量方法を確立した.
\end{abstract}

\section{1 緒言}

ジアンチピリルメタン (DAM) 誘導体の分析化学的 研究に関してはこれまで主としてソ連の研究者により 研究され，かなりの報告が見受けられる1). 今回取り 上げたジアンチピリルー2-ヒドロキシフェニルメタン (DHPM) は DAM の中心のメタンの水素を 2-ヒドロ

* 東北大学非水溶液化学研究所：宮城県仙台市片平 2-1-1

** 東北大学工学部応用化学科 : 宮城県仙台市荒巻字青 葉
キシフェニル基で置き替えたもので，この化合物の分析 化学的応用例としてはチタンの沈殿分離ならびに検出に ついての報告2)があるだけでほかには見あたらないよう である，そこで著者らはDHPM の分析試薬としての利 用につき種々検討した結果，この試薬はチタン (IV) を はじめ, 種々のイオンと錯体を形成するが，それらの多く は無色であるのに反しチタン(IV) 錕体は買色を呈する こと，およびチタン(IV) 錯体は過塩素酸イオンやチオ シアン酸イオンなどのアニオンの存在下ではジクロルエ タン，メチルイソブチルケトン (MIBK) などの有機溶 媒に定量的に抽出されることがわかったので，この試薬 
をチタンの発色試薬として使用できると考え，種々検討 した結果, DHPM が微量チタンの吸光光度定量試薬と して特に選択性の点ですぐれており，感度の点でもそん 色なく，きわめて実用的な試薬であることがわかった.

\section{2 試薬および装置}

\section{1 試 薬}

DHPM 溶液: $0.7 \%$ メタノール溶液として用いた. DHPM 泟サチルアルデヒドとアンチピリンとから Kanaev の方法3)により合成した．収率：約 $90 \% ， \mathrm{mp}$ $150 \sim 151^{\circ} \mathrm{C}$, 水には溶けないが，低級アルコール，有 機溶媒に可溶.

チタン $(\mathrm{IV})$ 標準溶液：三酸化チタン $0.45 \mathrm{~g}$ を $8 \mathrm{~g}$ の重硫酸カリウムで融解し, 硫酸 $(1+19)$ に溶かして $250 \mathrm{ml}$ とした，標定はアンモニア水を用いる重量分析 法によったとの溶液を硫酸 $(1+19)$ で適当にうすめ て使用した。

その他の茑薬類はすべて特級品を使用した。

\section{2 装}

吸光度の測定：日立-Perkin Elmer 分光光度計 139 型（10 mm 石英セル）を使用した.

$\mathrm{pH}$ の測定：東覀電波製 ガラス電極 $\mathrm{pH}$ メーター HM-5A 型を使用した。

抽出時の振り混ぜはイワキ製 $\mathrm{KM}$ 式万能シェーカー VS 型を使用した。

\section{3 定量方法}

\section{1 発色操作および吸光度の測定}

チタン (IV) $120 \mu \mathrm{g}$ 以下を含む溶液を $25 \mathrm{ml}$ のメス フラスコにとり, 硫酸 $(1+19)$ または塩酸 $(1+6) 1 \mathrm{~m} l$ を加えたのち水で適当にうすめる. 必要があれば 鉄 (III)，バナジウム $(\mathrm{V})$ またはクロム $(\mathrm{VI})$ が存在する 場合子䢙元剂として $10 \%$ アスコルビン酸溶液 $1 \mathrm{ml}$ を 加光，約 1 分間放置する. これに $0.7 \%$ DHPM のメタ ノール溶液 $5 \mathrm{ml}$ を加え, 水で標線までうすめる. 20 分 間放置したのち試薬ブランク液を対照として波長 347 $\mathrm{nm}$ で吸光度を測定する. チタン(IV) 標準溶液を用い, 同様の操作により作成した検量線からチタン含有量を求 める.

もしこのようにして得られた呈色液の吸光度が著しく 小さいと予想された場合には次に述べる抽出操作を行な う. すなわち, 呈色液を分液漏斗に移し, 少量の水でメ スフラスコを洗ってその洗液も分液漏斗に加える. これ に $1 M$ 過塩素酸ナトリウム溶液 $4 \mathrm{~m} l$ および 1,2 -ジク ロルエタン $10.0 \mathrm{ml}$ を加光, シェーカーを用いて 2 分 間振り混ぜる.しばらく静置して 2 層に分離したなら， 約 $1 \mathrm{~g}$ の無水硫酸ナトリウムを入れてある共せんびんに
有機相を移して脱水し，同様の操作により得た試薬ブラ ンク液を対照として波長 $338 \mathrm{~nm}$ で吸光度を測定する. この場合の検量線は同様の抽出操作を行なって作成した ものを用いる.

\section{2 カオリン中のチタンの定量操作}

試料 $0.5 \mathrm{~g}$ をはかりとり, 常法4)により炭酸ナトリウ ム融解, フッ化水素酸処理, ピロ硫酸ナトリウム融解を 行ない，最終的に $250 \mathrm{~m} l$ 定容の酸性溶液を調製する. この溶液 $5 \mathrm{~m} l$ を $25 \mathrm{~m} l$ のメスフラスコ中に 分取し, 以後 $3 \cdot 1$ に徉って操作与る.

\section{4 実験，結果抢よび考察}

\section{1 吸収曲線}

チタン (IV) は酸性で DHPM と反忍して黄色の錯体 を形成する. この場合 DHPM はチタンに対して大過剩 に加える必要があった. Fig. 1 にチタン(IV)-DHPM 錯体の水ーメタノール溶液中における吸収曲線を示した。 吸収極大は $347 \mathrm{~nm}$ 付近に認められた.この錯体は過塩 素酸，チオシアン酸，臭素などのアニオンの共存下では ジクロルエタンに抽出され，Fig. 1 と類似の吸収曲線を 与えるが，その場合には吸収極大は約 $10 \mathrm{~nm}$ ほど短波 長側に移行し， $338 \mathrm{~nm}$ 付近に認められた.

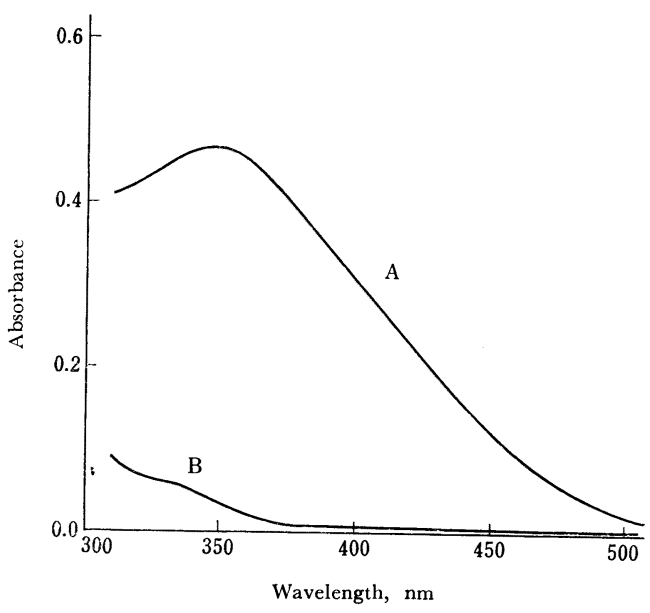

Fig. 1 Absorption curves $\mathrm{Ti}(\mathrm{IV}): 2.5 \mathrm{ppm}$; Concn. of $\mathrm{H}_{2} \mathrm{SO}_{4}: 0.07 N$ (Apparent $\mathrm{pH} \doteqdot 1.6)$; Concn. of DHPM : $0.14 \%$; Methanol content : 20\%; $\mathrm{A}: \mathrm{Ti}(\mathrm{IV})$-DHPM complex against reagent blank; B : Reagent blank against 20\% methanol

\section{2 酸濃度の影響}

発色に及ぼす 硫酸濃度の影響を 調べた結果は Fig. 2 


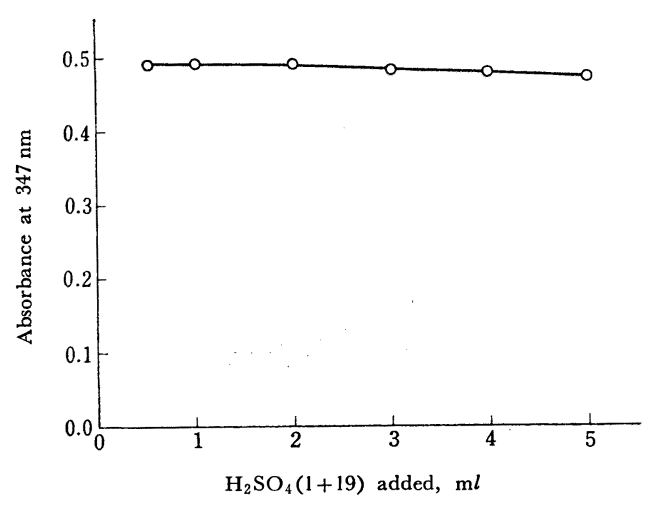

Fig. 2 Influence of $\mathrm{H}_{2} \mathrm{SO}_{4}$ concentration Ti(IV) : $2.6 \mathrm{ppm}$; Concn. of DHPM : $0.14 \%$; Methanol content : 20\%; Reference : Reagent blank

に示したとおりで, 最終液量 $25 \mathrm{~m} l$ に対し, 硫酸 $(1+$ 19) 添加量 $0.5 \sim 2 \mathrm{ml}$ の場合に吸光度は一定となり, それ以上硫酸濃度を増加すると吸光度はわずかずつ減少 する傾向が認められた，また硫酸濃度が著しく低い場合 には発色はすみやかであるが（後述のように酸濃度は発 色時間にも影響する)，過剩の DHPM が沈殿して濁り を生じ，吸光度の測定が不可能であった. 硫酸 $(1+19)$ の代わりに塩酸 $(1+6)$ を用いても同様の結果が得られ た.したがって酸は最終液量 $25 \mathrm{ml}$ に対し硫酸 $(1+19)$ または塭酸 $(1+6)$ を $1 \mathrm{~m} l$ 添加することにした（見か けの $\mathrm{pH}$ は約 1.6 になる).

\subsection{DHPM 濃度の影響}

予備実験の結果によれば既述したように，発色にはチ タンに対し大過剩の DHPM が必要であった（チタンに 対しモル比で 10 倍程度ではほとんど発色しなかった） ので発色に及ぼす DHPM 濃度の影響を調べた. 結果は Fig. 3 に示したとおりで, DHPM 濃度を増加するにつ れて吸光度も増加するが，0.7\% DHPM のメタノール 溶液添加量 $4 \mathrm{ml}$ 以上では吸光度の増加は無視しうる程 度であること，さらに，DHPM 濃度が低い場合には最 高呈色強度を与えるに要する時間が長いことがわかっ た.したがって DHPM 溶液の添加量はこの結果ならび に酸濃度の影響，さらに後述のメタノール量の影響，発 色に要する放置時間などをも考慮して $0.7 \%$ メタール 溶液を $5 \mathrm{ml}$ 添加することにした（最終液量 $25 \mathrm{ml}$ 中の 濃度に換算すると $0.14 \%$ に相当する).

\section{4 メタノール量の影響}

DHPM は水に不溶なためメタノール溶液として添加

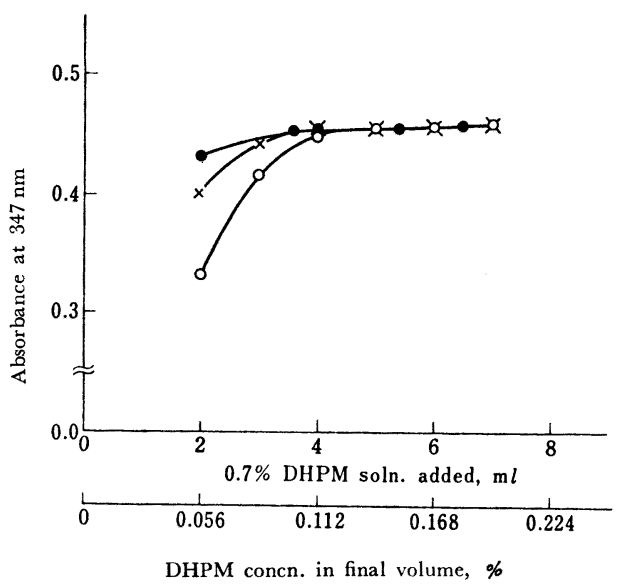

Fig. 3 Influence of DHPM concn.

$\mathrm{Ti}$ (IV) : $2.4 \mathrm{ppm}$; Concn. of $\mathrm{H}_{2} \mathrm{SO}_{4}: 0.07 N$ (Apparent $\mathrm{pH} \doteqdot 1.6)$; Methanol content : 20\%; Reference

: Reagent blank; Standing time : $-\mathrm{O}-20 \mathrm{~min}$,

$-x-40 \mathrm{~min},-0-60 \mathrm{~min}$

することにしたのでメタノール量の影響を調べた・結果 は Fig. 4 に示したとおりで，メタノール濃度 $16 \%$ 以 上で一定の吸光度が得られた.なお，メタノール濃度 10\% 以下の場合には過剰の DHPM が析出し，濁りを 生じた.

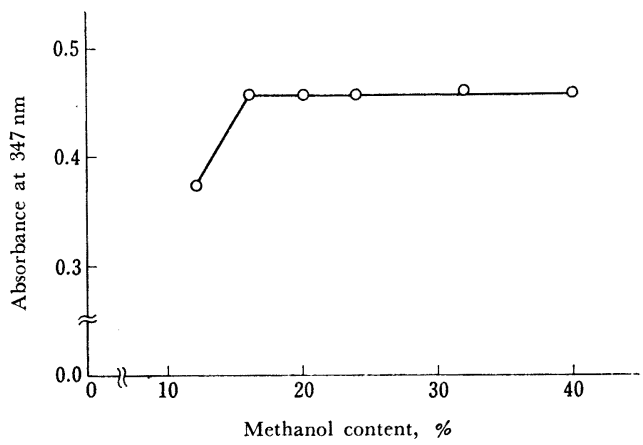

Fig. 4 Influence of methanol content $\operatorname{Ti}(\mathrm{IV}): 2.4 \mathrm{ppm}$; Concn. of DHPM : 0.14\%; Concn. of $\mathrm{H}_{2} \mathrm{SO}_{4}: 0.07 \mathrm{~N}$ (Apparent $\mathrm{pH} \fallingdotseq 1.6$ ); Reference : Reagent blank

\section{5 放置時間の影響}

既述の実験結果からも推察されるように，DHPM 濃 度が低いほど，また酸濃度が高いほど最高呈色強度を得 るには長時間を要したが，3.1 に示した定量条件に従っ た場合には DHPM 溶液添加後約 15 分間放置すれば吸 光度は一定かつ最大值を示し, 以後 3 時間までの測定で 
は吸光度にまったく变化が認められなかった。

\section{6 チタン濃度と吸光度との関係}

$3 \cdot 1$ の操作に従って水ーメタノール系溶液中で発色さ せ，検量線を作成したところ，少なくともチタン 120 $\mu \mathrm{g}$ (約 $4.8 \mathrm{ppm}$ に相当）までは原点を通る直線となり， これから計算したモル吸光係数は $9.1 \times 10^{3} \mathrm{l} / \mathrm{mol} \cdot \mathrm{cm}$, 吸光度 0.001 に対する感度は $5.3 \times 10^{-3} \mu \mathrm{g} \mathrm{Ti} / \mathrm{cm}^{3}$ で あった。

\section{7 共存イオンの影響と対策}

種々のイオンを単独でチタン(IV) と共存させた場合 の影響を調べた結果を Table I に示した. 鉄(III)，バ ナジウム (V) は DHPM と可溶性錯体を形成すること により正の誤差を, クロム(VI), 過塩素酸塩, ヨウ化 物，チオシアン酸塩は DHPM と反応して沈殿を生じ, 酒石酸塩, クエン酸䘏はチタン (IV) と錯体を形成する ことにより負の䛊差を生じた. そのほかジルコニウム (IV) も多量に存在すると定量を妨害した.

これら妨害イオンのうちクロム(VI), 鉄(III), バナ ジウム $(\mathrm{V})$ による妨害は DHPM 溶液添加に先だち $10 \%$

Table I Influence of diverse ions

\begin{tabular}{|c|c|c|c|}
\hline Ion & Ion added & Ti found (ppm) & Relative error $(\%)$ \\
\hline $\mathrm{Ag}(\mathrm{I})$ & $200 \mathrm{ppm}$ & 2.48 & 0.8 \\
\hline $\mathrm{Al}(\mathrm{III})$ & $200 " \prime$ & 2.46 & 0.0 \\
\hline $\mathrm{Ca}(\mathrm{II})$ & $200 \quad 11$ & 2.48 & 0.8 \\
\hline Cd(II) & 200 & 2.47 & 0.4 \\
\hline $\mathrm{Co}(\mathrm{II})$ & 20011 & 2.45 & -0.4 \\
\hline $\operatorname{Cr}(\mathrm{III})$ & 200 & 2.48 & 0.8 \\
\hline $\operatorname{Cr}(\mathrm{VI})$ & 50 & \multicolumn{2}{|c|}{ Precipitation was noticed } \\
\hline $\mathrm{Cu}(\mathrm{II})$ & 200 & 2.45 & -0.4 \\
\hline $\mathrm{Fe}(\mathrm{II})$ & $100 " \prime$ & 2.47 & 0.4 \\
\hline $\mathrm{Fe}(\mathrm{III})$ & $0.8^{\prime \prime}$ & 2.60 & 5.7 \\
\hline $\mathrm{Hg}(\mathrm{II})$ & $200 \quad \prime \prime$ & 2.46 & 0.0 \\
\hline $\mathrm{Mg}(\mathrm{II})$ & $200 " \prime \prime$ & 2.46 & 0.0 \\
\hline $\mathrm{Mn}(\mathrm{II})$ & $200 " \prime$ & 2.45 & -0.4 \\
\hline $\mathrm{Ni}(\mathrm{II})$ & $200 " 11$ & 2.45 & -0.4 \\
\hline $\mathrm{V}(\mathrm{IV})$ & 200 & 2.46 & 0.0 \\
\hline$V(V)$ & 20 & 2.83 & 15.0 \\
\hline $\mathrm{Zn}(\mathrm{II})$ & 200 & 2.46 & 0.0 \\
\hline $\mathrm{Zr}(\mathrm{IV})$ & 10 & 2.44 & -0.8 \\
\hline " & $20 " \prime$ & 2.42 & -1.6 \\
\hline$" \prime$ & $40 \prime \prime$ & 2.27 & -7.7 \\
\hline $\mathrm{Cl}^{-}$ & $0.5 \%$ & 2.46 & 0.0 \\
\hline $\mathrm{ClO}_{4}^{-}$ & $0.4^{\prime \prime}$ & \multicolumn{2}{|c|}{ Precipitation was noticed } \\
\hline $\mathrm{Br}^{-}$ & $0.4^{\prime \prime}$ & 2.46 & 0.0 \\
\hline $\mathrm{I}^{-}$ & $0.4^{\prime \prime}$ & \multicolumn{2}{|c|}{ Precipitation was noticed } \\
\hline $\mathrm{NO}_{3}^{-}$ & $0.5^{\prime \prime}$ & 2.47 & 0.4 \\
\hline $\mathrm{SCN}^{-}$ & $0.5^{\prime \prime}$ & \multicolumn{2}{|c|}{ Precipitation was noticed } \\
\hline acetate & $0.5^{\prime \prime}$ & 2.46 & 0.0 \\
\hline tartrate & $0.5^{\prime \prime}$ & 2.21 & -10.2 \\
\hline citrate & $0.5^{\prime \prime}$ & 2.12 & -13.8 \\
\hline
\end{tabular}

Ti(IV) taken : $2.46 \mathrm{ppm}$
アスコルビン酸溶液 $1 \mathrm{~m} l$ を添加し, それぞれクロム (III), 鉄(II), バナジウム (IV) に還元しておくことに よりほぼ完全に除去することができた（Table II）。 ま た過塩素酸塩, ヨウ化物, チオシアン酸塩が共存する場 合は後述のように発色液をジクロルエタンで抽出し, 抽 出液の吸光度を測定すればこれらのイオンは妨害しない ことがわかった. したがって本法では多量のジルコニウ ム (IV), 酒石酸塩, クエン酸塩以外の 通常のイオンは 妨害せず，選択性がきわめてすぐれている.

Table II Removal of interferences due to $\mathrm{Cr}(\mathrm{VI})$, $\mathrm{Fe}(\mathrm{III})$ and $\mathrm{V}(\mathrm{V})$ by addition of $1 \mathrm{ml}$ of $10 \%$ ascorbic acid

\begin{tabular}{cccc}
\hline Ion & $\begin{array}{c}\text { Ion added } \\
(\mathrm{ppm})\end{array}$ & $\begin{array}{c}\text { Ti found } \\
(\mathrm{ppm})\end{array}$ & $\begin{array}{c}\text { Relative error } \\
(\%)\end{array}$ \\
\hline $\mathrm{Cr}(\mathrm{VI})$ & 200 & 2.45 & -0.4 \\
$\mathrm{Fe}(\mathrm{III})$ & 50 & 2.46 & 0.0 \\
$\prime \prime$ & 100 & 2.47 & 0.4 \\
$\mathrm{~V}(\mathrm{~V})$ & 100 & 2.46 & 0.0 \\
$\prime \prime$ & 200 & 2.46 & 0.0 \\
\hline
\end{tabular}

Ti(IV) taken : $2.46 \mathrm{ppm}$

\section{8 錯体の抽出について}

既述のようにチタン(IV)-DHPM 錯体は過塩素酸, チオシアン酸, 臭化物などのアニオンの共存下では, こ れらとおそらくイオン対を形成するためと思われるが， ジクロルエタン, クロロホルム, MIBK などの有機溶 媒に抽出されるので, 水一メタノール系溶液中で発色さ せて得られた呈色液の呈色強度が小さい場合には，この 呈色液を適当な有機溶媒で抽出して濃縮することにより 測定の精度, 正確さを向上させ, さらに定量下限を引き 下げうると考え, 呈色液の抽出につき検討を加えた.

4.8.1 アニオンの選択と添加量 アニオンとしては 過塩素酸, チオシアン酸, 臭素, ヨウ素, 塩素イオンを 添加して錯体の抽出挙動を検討した結果, イオン半径が 比較的大きい過塩素酸イオンやチオシアン酸イオンを添 加した場合には錯体の抽出はほぼ完全であったが, 塩素 イオンを添加した場合には抽出は不完全で, 錯体の一部 が抽出されるにすぎなかった. 臭素イオンやヨウ素イオ ンを添加した場合も抽出はほぼ定量的であったが, 後者 の場合には少量遊離したヨウ素が抽出され, 吸光度にば らつきを生ずるので好をしくなかった。

以上の結果から添加するアニオンとしては過塩素酸ま たはチオシアン酸イオンが適当と考えられたが, 後者の 場合はこれと有色の錯体を形成する金属イオンが共存す るときはそれらも抽出されてチタンの定量を妨害し, 選 択性を低下させるので好ましくなく, 添加するアニオン 
としては過塩素酸イオンが最も適当で，その添加量は $1 M$ 溶液 $3 \mathrm{ml}$ 以上加えればじゅうぶんであった。

4.8.2 抽出溶媒の選択 1,2-ジクロルエタン, クロ ロホルム，MIBK，ベンゼンを用いて抽出挙動を調べた ところ，錯体はベンゼンにはごく一部分抽出されるだけ であったが，他の溶媒には定量的に抽出され，それらの なかでは抽出液の安定性, 錯体ならびに試薬の溶解度, 感度などの点でジクロルエタンが最も適当と考えられ た。

上記 4.8.1 に述べた結果をも考慮して錯体の抽出は呈 色液に $1 M$ 過塩素酸ナトリウム溶液 $3 \mathrm{~m} l$ を加え, シ クロルエタン $10.0 \mathrm{~m} l$ を用いて行なうこととし，以後 の検討はこれに従って行なった。

4.8.3 振り混ぜ時間の影響 振り混ぜ時間を 1 分か ら 10 分まで変化させて抽出実験を行なった結果，2分 間以上振り混ぜれば一定の吸光度が得られることがわか った.

4.8.4 抽出率と安定性錯体の抽出率を 調べるた め, チタン(IV) $20.0 \mu \mathrm{g}$ をとり，3.1 の操作に準じて 錯体を抽出し，その際得られた水相に新たに DHPM 溶 液および過塩素酸ナトリウム溶液を加え, ジクロルエタ ンで抽出をくりかえし，そのつど有機相の吸光度を測定 してみたが，2 回め以降の抽出操作により得られた有機 相については錯体の生成に基うくく吸収は認められなかっ た.したがって錯体は 1 回の抽出操作によりほぼ完全に 抽出されることがわかった。 また有機相の吸光度は抽出 後 60 分までの測定ではまったく変化しなかった.

4.8.5 検量線 原点を通る良好な直線性を示し, 見 かけのモル吸光係教は $1.0 \times 10^{4} \mathrm{l} / \mathrm{mol} \cdot \mathrm{cm}$ であった.

4.8.6 共存イオンの影響 水ーメタノール系で発色 させて吸光度を測定する場合（抽出しない場合）に妨害 となった過塩素酸, ヨウ素, チオシアン酸イオンはまっ たく妨害せず，その他のイオンについては Table I と 同様の結果が得られ，選択性はきわめてすぐれているこ とがわかった.

なお，添加アニオンとして過塩素酸イオンの代わりに チオシアン酸イオンを用いた場合には銅(II)，コバルト (II)， バナジウム $(\mathrm{IV}, \mathrm{V})$, 鉄(III) などチオシアン酸 イオンと錯体を形成するイオンは大なり小なり抽出され るので妨害し，逆に抽出することにより選択性は低下し た.

\section{9 実試料分析への応用例}

カオリン中のチタンの定量を行ない（この場合，水メタノール系で発色させて得られた呈色液の吸光度が測
定にじゅうぶんであったので，あえて抽出は行なわなか った), 過酸化水素法5) による結果と比較し, Table III に示した。なお，過酸化水素法の場合には試料溶液 250 $\mathrm{m} l$ から $50 \mathrm{ml}$ を分取し, 水浴上で加熱濃縮後発色させ た. Table III より本法は正確さ, 再現性ともにじゅう ぶえ満足しうるものと考えられる.

Table III Determination of $\mathrm{TiO}_{2}$ in kaolin

\begin{tabular}{cc}
\hline \multicolumn{2}{c}{$\mathrm{TiO}_{2}(\%)$} \\
\cline { 2 - 2 } DHPM method & $\mathrm{H}_{2} \mathrm{O}_{2}$ method \\
\hline 0.47 & 0.48 \\
0.48 & 0.48 \\
0.46 & 0.45 \\
av. 0.47 & av. 0.47 \\
\hline
\end{tabular}

\subsection{0 他の方法との比較}

本法は感度の点では著者のひとりがさきに報告した DAM 法6)（モル吸光係教 $15000 \mathrm{l} / \mathrm{mol} \cdot \mathrm{cm}$ )には及ばな いが，過酸化水素法 $\left(680 \mathrm{l} / \mathrm{mol} \cdot \mathrm{cm}^{7}\right)$ に比べればはる かに高く，特に通常のイオンでは妨害するものがほとん ぞないのできわめて実用的な方法と考えられる.

\section{5 結 言}

ジアンチピリルメタン誘導体の一つである DHPM を 用いる微量チタンの吸光光度定量につき検討し, 実用的 な定量方法を確立した。本法をカオリン中のチタンの定 量に応用して満足しうる結果を得た。 $\left(\begin{array}{l}1973 \text { 年 } 11 \text { 月, 日本分析化学 } \\ \text { 会第 } 22 \text { 年会に打いて発表 }\end{array}\right)$

\section{交献}

1) 石井 一 : 本誌, 21, 665 (1972).

2) R. G. Beiles : Zavodsk. Lab., 22, 1296 (1956) ; Anal. Abstr., 4, 1801 (1957).

3) N. A. Kanaev :J. Anal. Chem. USSR, 18, 496 (1963).

4) JIS M 粘土分析方法 (案).

5) E. B. Sandell : "Colorimetric Determination of Traces of Metals", 3rd Ed., p. 874 (1959), (Interscience Publishers, Inc., New York).

6) 石井 一 : 本誌, 16, 110 (1967).

7) E. B. Sandell : "Colorimetric Determination of Traces of Metals", 3rd Ed., p. 870 (1959), (Interscience Publishers, Inc., New York).

\section{拧}

Spectrophotometric determination of titanium with diantipyryl-2-hydroxyphenylmethane. Hajime IsHII* and Toshinori HiguchI** (*Chemical Research Institute of Non-Aqueous Solutions, Tohoku University, 2-1-1, Katahira, Sendai-shi, Miyagi; **Department of Applied Chemistry, Faculty of Engineering, 
Tohoku University, Aoba, Aramaki, Sendai-shi, Miyagi)

A selective method is reported for the spectrophotometric determination of small amounts of titanium. The method is based on the complex formation of titanium (IV) with diantipyryl-2-hydroxyphenylmethane (DHPM).

Titanium(IV) forms a stable and yellow complex with DHPM in an aqueous methanolic medium. The complex has an absorption maximum at approximately $347 \mathrm{~nm}$, and can be extracted quantitatively into dichloroethane in the presence of anions such as perchlorate, thiocyanate and iodide. Fundamental conditions for the determination of titanium including effects of concentrations of acid, DHPM and methanol, effect of standing time, extractability of the complex, etc. were studied and a practical method for the determination was established.

The outline of the procedure is as follows; Transfer the sample solution containing less than $120 \mu \mathrm{g}$ of titanium(IV) into a $25-\mathrm{m} l$ volumetric flask and add $1 \mathrm{~m} l$ of sulfuric acid $(1+19)$ or hydrochloric $\operatorname{acid}(1+6)$. If necessary, add $1 \mathrm{ml}$ of $10 \%$ ascorbic acid solution. Then add $5 \mathrm{ml}$ of $0.7 \%$ DHPM solution in methanol and dilute to the mark with water. After standing for 20 minutes, measure the absorbance of the solution at $347 \mathrm{~nm}$ against a reagent blank solution. If the absorbance of the colored solution is too low to measure, transfer all of the colored solution into a $50-\mathrm{m} l$ separatory funnel, and add $4 \mathrm{ml}$ of $1 M$ sodium perchlorate solution and $10.0 \mathrm{ml}$ of dichloroethane. Extract titanium(IV) complex by shaking for 2 minutes, and measure the absorbance of the organic phase at $338 \mathrm{~nm}$ against a reagent black solution prepared in the similar manner.

Under the optimum conditions, a good linear relationship between the absorbance and the concentration of titanium was obtained up to at least $4.8 \mathrm{ppm}$ titanium and the molar absorptivity at $347 \mathrm{~nm}$ was $9.1 \times$ $10^{3} \mathrm{l} / \mathrm{mol} \cdot \mathrm{cm}$.

Iron(III), vanadium(V), chromium(VI), large amounts of zirconium(IV), perchlorate, iodide, thiocyanate, tartrate and citrate interfered with the determination, but the other common ions did not interfere. Interferences by iron(III), vanadium(V) and chromium (VI) could be eliminated by reduction of these ions with ascorbic acid. Interferences by perchlorate, iodide and thiocyanate could be removed by extracting the colored solution with dichloroethane.

The method established was applied to the determination of titanium in kaolin and a satisfactory result was obtained.

(Received May 11, 1974)

\title{
ベリリウムと 5-ヒドロキシフラボン，5-ヒドロキシイソ フラボンおよびそれらの誘導体とのけい光反応
}

\author{
村田 旭，富永 正憲，鈴木 哲夫*
}

(1974 年 5 月 13 日受理)

ヘリリウムと 5-ヒドロキシフラボン，5-ヒドロキシイソフラボンおよびこれらの誘導体 8 種とのけ い光反応を検討し，置換基の種類と位置とが錯体のけい光特性に与える影響を明らかにした. これらの 試薬はいずれもベリリウムと黄色錯体を生成し，四塩化炭素に抽出されて黄緑色のけい光を発する. 錯 体のけい光強度はイソフラボンの 2 位にアルキル基特にエチル基を置換すると大きくなり，さらに 7 位 にメトキシル基を置換した 2-エチル-5-ヒドロキシー7-メトキシイソフラボンが最大であった（励起波 長 $366 \mathrm{~nm}$ 水銀輝線). これを利用するべリリウムのけい光光度定量法についても検討した.

\section{1 緒言}

さきに，ベリリウムと 5-ヒドロキシクロモンおよび その誘導体 13 種とのけい光反応を検討し, 置換基の種 類と位置とが錯体のけい光特性に与える影響を明らかに

$*$ 静岡大学工学部: 静岡県浜松市城北 3-5-1
するとともに1)，最適の試薬と考えられる 2-エチル-3メチル-5-ヒドロキシクロモンによるベリリウムのけい 光光度定量について報告した2). また 5-ヒドロキシクロ モンの 2,3-ベンゾ誘導体である 1-ヒドロキシキサント ンおよびそのメチル誘導体 5 種とベリリウムとのけい光 反応についても検討し, 最適試薬と考えられる1-ヒド 